\title{
Short Letrozole Therapy Vs Extended (Long) Letrozole Therapy for Induction of Ovulation in Women with Polycystic Ovary Syndrome
}

Mahmoud M. A. El-Aziz, Mohamed S. Fouad, Tamer F. Ouf

Department of Obs. \& Gyn., Faculty of Medicine, Al-Azhar University, Cairo, Egypt. Corresponding author: Mahmoud M. A. Aziz, E-Mail: drmabdelaziz04@gmail.com, Mobile: +201008688781

\begin{abstract}
Background: polycystic ovary syndrome (PCOS) is the major cause of anovulatory infertility. Letrozole and other aromatase inhibitors (AIs) have been introduced as a new treatment option could challenge clomiphene citrate $(\mathrm{CC})$ for ovulation induction in this group.

Objective: to compare the efficacy of short vs extended courses of letrozole therapy for ovulation induction in PCOS women. Patients and Methods: this is prospective randomized comparative study done on 60 patients attended El-Hussein Hospital and previously diagnosed as having PCOS, based on the revised Rotterdam criteria (2003). Patients were divided randomly into 2 treatment groups, group I, short letrozole therapy (30 patients, received $5 \mathrm{mg}$ of letrozole from $1^{\text {st }}$ to $5^{\text {th }}$ day of menstrual bleeding) and group II, long letrozole therapy (30 patients, received $2.5 \mathrm{mg}$ of letrozole from $1^{\text {st }}$ to $10^{\text {th }}$ day of menstrual bleeding). All patients of both groups monitored by trans-vaginal ultrasound on day 10 of the cycles. HCG injection $(5,000$ IU IM) was given when at least one follicle measured $\geq 18 \mathrm{~mm}$. Intercourse were advised for 24-36h after HCG injection. Serum HCG and trans-vaginal ultrasound were done 2 weeks after HCG injection in the absence of menstruation for diagnosis of pregnancy.

Results: in long letrozole therapy, total number of follicles, mean number of mature follicles, endometrial thickness, percentage of patients ovulated after treatment, occurrence of pregnancy were greater when compared to results of short letrozole therapy.

Conclusion: long letrozole therapy can produce more mature follicles and subsequently more pregnancies than short letrozole therapy.
\end{abstract}

Keywords: polycystic ovary syndrome, letrozole.

\section{INTRODUCTION}

Polycystic Ovary Syndrome (PCOS) is one of the most common causes of anovulatory infertility, affecting $8-13 \%$ of reproductive-aged women ${ }^{(1)}$. It is by far the most common cause of hyperandrogenic anovulatory infertility and was described more than half a century ago, the underlying cause of this disorder is still uncertain (2). The classic symptoms of the disease are due to increased ovarian androgen production and chronic anovulation (3). There are several clinical and laboratory criteria such as obesity, acanthosis nigricans, oligomenorrhea, hirsutism and acne. Also, there may be an increase luteinizing hormone to follicle-stimulating hormone ratio ( $\mathrm{LH} / \mathrm{FSH})$, as well as decreased ovulatory rate ${ }^{(4)}$.

Criteria used for diagnosing Polycystic Ovary Syndrome (PCOS) are the Rotterdam Criteria (2003) of which a woman must have two out of the followings:

1- Oligo- or anovulation.

2- Clinical and / or biochemical signs of hyperandrogenism

3- Polycystic ovaries (with the exclusion of related disorders).

Aromatase inhibitors (AIs) have been introduced as a new treatment option that could challenge $\mathrm{CC}$ for ovulation induction ${ }^{(5)}$.
Aromatase is a cytochrome $\mathrm{P}-450$ hem protein containing enzyme complex (the product of the CYP19 gene) that catalyzes the rate-limiting step in the production of estrogens which is the conversion of androstenedione and testosterone via three hydroxylation step to estrone and estradiol ${ }^{\left({ }^{(6)}\right.}$.

Aromatase activity is present in many tissues such as the ovaries, adipose tissue, muscle, liver, breast tissue, and in malignant breast tumors. In premenopausal women, estrogens are produced primarily in the ovaries, corpus luteum, and placenta, although a small but significant amount of estrogens can also be produced by nongonad organs, such as the liver, heart, skin, and brain. E2 is the major product from the whole biosynthesis process and is the most potent estrogen during the premenopausal period in a woman's life, whereas E1 plays a larger role after menopause, when it is synthesized in adipose tissue from adrenal dehydroepiandrosterone ${ }^{(7)}$.

Types of aromatase inhibitor (AIs): AIs all powerfully inhibit estrogen synthesis, they may be subdivided into steroidal (type I) and nonsteroidal (type II) inhibitors, which interact with the aromatase enzyme ${ }^{(8)}$. Type II non-steroidal AIs exert their function through binding to the heme moiety of the cytochrome P-450 enzyme (9), whereas steroidal AIs may bind covalently and irreversibly to the aromatase enzyme. 
Anastrozole and letrozole are third generation selective (nonsteroidal) AIs, available for clinical use for treatment of postmenopausal breast cancer, they are reversible, competitive AIs, which are highly potent and selective ${ }^{\mathbf{( 1 0 )}}$.

The high affinity of AIs for aromatase is thought to reside in the $\mathrm{N}-4$ nitrogen of the triazole ring that coordinates with the heme iron atom of the aromatase enzyme complex.

Letrozole is rapidly absorbed from the gastrointestinal tract and excreted by the kidney. The elimination half-life of letrozole is about 2 days (11).

AIs can be applied for ovarian stimulation as its administration early in the follicular phase can induce ovulation by releasing the hypothalamus or pituitary from estrogen negative feedback on GnRH and gonadotropin secretion, leading to an increase in gonadotropin production which would stimulate ovarian follicular development ${ }^{(\mathbf{1 2})}$.

AIs prevent the Androgen-Estrogen conversion and therefore interfere with the negative feedback at the level of the hypothalamus-pituitary. The increased pituitary gonadotropin output will in turn stimulate the ovaries ${ }^{(\mathbf{1 3})}$.

Also, they act locally in the ovary to increase follicular sensitivity to FSH. This may result from accumulation of intraovarian androgens, since conversion of androgen substrate to estrogen is blocked. Recent data support a stimulatory role for androgens in early follicular growth ${ }^{(\mathbf{1 4})}$.

In some studies, letrozole in contrast to $\mathrm{CC}$ is better as it increases endometrial thickness by upregulation of estrogen receptors, so it increases pregnancy rate and also it decreases incidence of multiple pregnancy ${ }^{(13)}$.

AIs reported to be effective in inducing ovulation, increased pregnancy rate, improve uterine environment, endometrial development with favorable cervical mucus ${ }^{\mathbf{1 3})}$.

\section{AIM OF THE WORK}

The aim of this study is to compare the efficacy of short course ( $5 \mathrm{mg}$ daily for 5 days) vs extended course (2.5mg daily for 10 days) of letrozole therapy for ovulation induction in women with polycystic ovary syndrome.

\section{PATIENTS AND METHODS}

Type of study: Prospective randomized comparative study.

Site of study: Obstetrics and Gynecology department, El-Hussein Hospital, Cairo, Egypt. The study was approved by the Ethics Board of Al-Azhar University.

Sample size: 60 infertile women diagnosed as having polycystic ovary syndrome based on the revised Rotterdam criteria (2003), attending the outpatient clinic of Obstetrics and Gynecology, ElHussein Hospital. Written consent will be obtained from the patients.

Groups of the study: Patients were randomly allocated using a computer-generated random table into 2 treatment groups:

Group I: Short letrozole therapy group (30 patients).

Group II: Long letrozole therapy group (30 patients).

Inclusion criteria:

1-Age: 18-35 years old.

2-Egyptian nationality.

3-Infertility $\geq 2$ years.

4-Diagnosis of PCOS according to Rotterdam Criteria.

5-Nonsmoker or addict to any substance.

6-One sexual partner (married).

Exclusion criteria:

1-History of pelvic surgery or trauma.

2-Women with infertility factors other than anovulation.

3-Male factor of infertility.

4-Not Egyptian.

5-Smokers, alcohol addict.

6-Multiple sexual partners.

All participating patients will have the following:

I-Full history:

- Personal history

- History of present illness

-Menstrual history

- Sexual history

- Past history

- Family history

II-Complete examination:

- General examination

- Abdominal examination

- Local (Pelvic) examination

III-Investigations:

- General (CBC, urinalysis, Random blood sugar) when needed.

-Specific: FSH, LH, Prolactin.

\section{Methodology:}

Patients of short letrozole therapy group (30 patients) were received $5 \mathrm{mg}$ of letrozole ( 2 tablets of letrozole $2.5 \mathrm{mg}$, Sandoz Pharmaceutical Company, Australia) daily starting from day 1 of spontaneous (or progesterone induced, using Medroxyprogesterone acetate $10 \mathrm{mg}$ tab, one tab daily for 5days) menstrual bleeding for 5 days (30 patients, up to 3 cycles).

Patients of long letrozole therapy group (30 patients) were received $2.5 \mathrm{mg}$ of letrozole (one tab of letrozole $2.5 \mathrm{mg}$, Sandoz Pharmaceutical Company, Australia) daily starting from day 1 of spontaneous (or progesterone induced) menstrual bleeding for 10 days ( 30 patients, up to 3 cycles). 
All patients of both groups were monitored by trans-vaginal ultrasound for the mean follicular volume and thickness of the endometrium on day 10 of the cycles. HCG injection (5,000 IUIM) was given when at least one follicle measured $\geq 18 \mathrm{~mm}$.

Patients were advised for intercourse 24-36h after HCG injection.

Serum HCG was determined 2 weeks after HCG injection in the absence of menstruation for diagnosis of pregnancy followed by trans-vaginal ultrasound for demonstration of the gestational sac.

\section{Statistical analysis}

Qualitative variables were summarized with absolute numbers and percentage and quantitative variables with means and standard deviation $(\mathrm{SD})$ .Continuous variables were compared using $\mathrm{t}$ Student test while categorical data were analyzed using the $\chi^{2}$ test.

\section{RESULTS}

- Total number of follicles during stimulation was significantly greater in the long letrozole group $(6.48 \pm 0.68)$ vs. $(4 \pm 0.91)$ in short letrozole group; $\mathrm{P}=0.001)$.

Table (1): Mean number of follicles in group I (short letrozole group) and group II (long letrozole group):

\begin{tabular}{|l|l|l|l|l|l|l|l|l|}
\hline \multicolumn{2}{|c|}{} & \multicolumn{3}{|c|}{$\begin{array}{l}\text { Short letrozole } \\
\text { group }(\mathrm{N}=18)\end{array}$} & \multicolumn{2}{|c|}{$\begin{array}{l}\text { Long letrozole group } \\
(\mathrm{N}=21)\end{array}$} & P-value \\
\hline \multirow{2}{*}{$\begin{array}{l}\text { Total number of } \\
\text { follicles }\end{array}$} & Range & 3 & - & 6 & 5 & - & 7 & \multirow{2}{*}{$<0.001$} \\
\cline { 2 - 9 } & $\begin{array}{l}\text { Mean } \pm \\
\text { S. D }\end{array}$ & 4 & \pm & 0.91 & 6.48 & \pm & 0.68 & \\
\hline
\end{tabular}

- The mean of biggest follicles size $(\mathrm{mm})$ was greater $(19.095 \pm 2.26)$ in the long letrozole group when compared to short letrozole group $(18.83 \pm 2.12)$, without statistical differences $(\mathrm{P}=0.712)$.

Table (2): Mean of the biggest follicles size in group I (short letrozole group) and group II (long letrozole group):

\begin{tabular}{|c|c|c|c|c|c|c|c|c|}
\hline \multicolumn{2}{|c|}{} & \multicolumn{3}{|c|}{$\begin{array}{l}\text { Short letrozole group } \\
(\mathrm{N}=18)\end{array}$} & \multicolumn{2}{c|}{$\begin{array}{l}\text { Long letrozole group } \\
(\mathrm{N}=21)\end{array}$} & \multirow{2}{*}{ P-value } \\
\hline \multirow{2}{*}{ Biggest follicles size } & Range & 16 & - & 24 & 16 & - & 25 & \multirow{2}{*}{0.712} \\
\cline { 2 - 9 } & Mean \pm S. D & 18.83 & - & 2.12 & 19.095 & \pm & 2.26 & \\
\hline
\end{tabular}

- The number of patients with follicles measuring $<14 \mathrm{~mm}$ was greater (40\%) in the short letrozole group compared to the long letrozole group (30\%), the number of patients with follicles measuring 14-17 mm was greater (16.7\%) in long letrozole group compared to short letrozole group (13.3\%), while the number of patients with follicles measuring $\geq 18 \mathrm{~mm}$ was greater (53.3\%) in the long letrozole group compared to the short letrozole group $(46.7 \%)$ without statistical significance $(\mathrm{P}=0.774)$.

Table (3): Number of patients with different follicle size in group I (short letrozole group) and group II (long letrozole group):

\begin{tabular}{|l|c|l|l|l|}
\hline \multicolumn{2}{|c|}{ Biggest follicle size } & Short letrozole group (N=30) & Long letrozole group (N=30) & P-value \\
\hline Patients with biggest & $\mathrm{N}$ & 12 & 9 & \\
\cline { 2 - 4 } follicles $<14$ & $\%$ & $40 \%$ & $30 \%$ & \\
\hline Patients with & $\mathrm{N}$ & 4 & 5 \\
\cline { 2 - 4 } follicles 14-17 & $\%$ & $13.3 \%$ & $16.7 \%$ & \\
\hline Patients with biggest & $\mathrm{N}$ & 14 & $53.3 \%$ \\
\cline { 2 - 4 } follicles $\geq 18 \mathrm{~mm}$ & $\%$ & $46.7 \%$ & 30 & \\
\hline \multirow{2}{*}{ Total } & $\mathrm{N}$ & 30 & $100 \%$ & \\
\cline { 2 - 4 } & $\%$ & $100.0 \%$ & $16 \%$ & \\
\hline
\end{tabular}

-The mean of endometrial thickness at HCG injection among group I (short letrozole group) and group II (long letrozole group) $\pm \mathrm{SD}$ was $8.2 \pm 1.56 \mathrm{~mm}$ versus $8.933 \pm 1.64$ respectively without significant difference between the two groups $(\mathrm{P}=0.081)$.

Table (4): Mean of Endometrial thickness at HCG (mm) in group I (short letrozole group) and group II (long letrozole group):

\begin{tabular}{|l|l|l|l|l|l|l|l|l|}
\hline \multicolumn{2}{|c|}{} & \multicolumn{3}{|c|}{$\begin{array}{l}\text { Short letrozole } \\
\text { group }(\mathrm{N}=30)\end{array}$} & \multicolumn{3}{|c|}{$\begin{array}{l}\text { Long letrozole } \\
\text { group }(\mathrm{N}=30)\end{array}$} & $\begin{array}{l}\text { P- } \\
\text { value }\end{array}$ \\
\hline \multirow{2}{*}{$\begin{array}{l}\text { Endometrial } \\
\text { thickness at } \\
\text { hCG (mm) }\end{array}$} & Range & 5 & - & 11 & 6 & - & 11 & \\
\cline { 2 - 9 } & Mean \pm & 8. & - & 1.56 & 8.93 & \pm & 1.6 & 0.081 \\
\hline
\end{tabular}

- Percentage of patients ovulated after treatment among group I (short letrozole group) and group II (long letrozole group) was $56.7 \%$ vs $63.3 \%$ respectively with significant difference between the two groups $(\mathrm{P}=0.598)$. 
Table (5): Percentage of ovulation occurred after treatment in group I (short letrozole group) and group II (long letrozole group):

\begin{tabular}{|c|c|c|c|c|}
\hline & & $\begin{array}{l}\text { Short letrozole } \\
\text { group } \\
(\mathrm{N}=30)\end{array}$ & $\begin{array}{l}\text { Long letrozole } \\
\text { group } \\
(\mathrm{N}=30)\end{array}$ & P-value \\
\hline \multirow{2}{*}{ No } & $\mathrm{N}$ & 13 & 11 & \multirow{6}{*}{0.598} \\
\hline & $\%$ & $43.3 \%$ & $36.7 \%$ & \\
\hline \multirow{2}{*}{ Yes } & $\mathrm{N}$ & 17 & 19 & \\
\hline & $\%$ & $56.7 \%$ & $63.3 \%$ & \\
\hline \multirow{2}{*}{ Total } & $\mathrm{N}$ & 30 & 30 & \\
\hline & $\%$ & $100.0 \%$ & $100 \%$ & \\
\hline
\end{tabular}

- Pregnancy occurred in 4 out of 30 patients in the short letrozole group (13.3\%) and in 6 out of 30 patients (20\%) in the long letrozole group. One twin pregnancy occurred in the long letrozole group (16.67\% of pregnant cases). Comparison between the groups according to post treatment pregnancies was statistically significant as $\mathrm{P}$ - value $=0.729$.

Table (6): Number of pregnancies after therapy in group I (short letrozole group) and group II (long letrozole group):

\begin{tabular}{|c|r|l|l|l|}
\hline \multicolumn{2}{|c|}{ Pregnancies } & $\begin{array}{l}\text { Short letrozole group } \\
(\mathrm{N}=30)\end{array}$ & $\begin{array}{l}\text { Long letrozole group } \\
(\mathrm{N}=30)\end{array}$ & \multirow{2}{*}{ P-value } \\
\hline \multirow{2}{*}{ No } & $\mathrm{N}$ & 26 & 24 & \\
\cline { 2 - 4 } & $\%$ & $86.7 \%$ & $80 \%$ & \multirow{2}{*}{0.729} \\
\cline { 2 - 4 } Yes & $\mathrm{N}$ & 4 & 6 & \\
\cline { 2 - 4 } & $\%$ & $13.3 \%$ & $30 \%$ & \\
\cline { 2 - 4 } Total & $\mathrm{N}$ & 30 & $100 \%$ & \\
\cline { 2 - 4 } & $\%$ & $100.0 \%$ & & \\
\hline
\end{tabular}

\section{DISCUSSION}

Polycystic ovary syndrome (PCOS) is one of the most causes that affect the women of childbearing age ${ }^{(\mathbf{1 5})}$, and often leads to infertility ${ }^{(\mathbf{1 6})}$. It is diagnosed based on the hyperandrogenism, oligomenorrhea, and polycystic ovaries on ultrasonography ${ }^{(17)}$. Its prevalence has been reported to vary from $6.8 \%$ to $18 \%$ according to the different diagnostic criteria ${ }^{(18)}$. Its symptoms often bring psychological disorders for patients with PCOS (20). These conditions often consist of depression, anxiety, irregular menstrual periods, and even the infertility ${ }^{(20)}$.

Various managements were proposed for infertile women with PCOS (21). However, the optimal management option has not been addressed satisfied.

Although multiple treatments including weight reduction, clomiphene citrate, metformin, gonadotropins, and ovary cauterization have been reported to treat such condition, the efficacy still has insufficient evidence to support ${ }^{(22)}$.

Clomiphene citrate, a selective estrogen-receptor modulator that antagonizes the negative feedback of estrogen at the hypothalamus with a consequent increase in ovarian stimulation by endogenous gonadotropin, has been used for this indication for decades. Clomiphene citrate (CC) has been the most widely used drug for the treatment of infertility since its introduction into clinical practice in the 1960s. It is known that clomiphene citrate results in an ovulation rate of $60-85 \%$ but a conception rate of only about $20 \%{ }^{(23)}$. CC has a long half-life (2 weeks), and this may have a negative effect on the cervical mucus and endometrium as it has a deleterious effect on cervical mucus quantity and quality and endometrial development resulting in decreased uterine blood flow, endometrial thinning, luteal phase defect and implantation failure, leading to discrepancy between ovulation and conception rates ${ }^{(24)}$.

Clomiphene has drawbacks, including its overall poor efficacy (only a $22 \%$ rate of live birth with up to six cycles of clomiphene in our previous study ${ }^{(25)}$, a relatively high multiple-pregnancy rate (3 to $8 \%$ ) as compared with the rate associated with unassisted conception $(<1 \%)$, and an undesirable side-effect profile, including mood changes and hot flushes. Failure either to ovulate (clomiphene resistance), which occurred in $25 \%$ of the patients treated with clomiphene (25), or to conceive with ovulation (clomiphene failure) treatment by $\mathrm{CC}$ also associated 
with higher multiple-pregnancy rates and an increased risk of the ovarian hyperstimulation syndrome ${ }^{(26)}$.

The development of effective, simple, and safe treatments for infertility is an important public health goal (27). Metformin improves insulin action and anovulation. However, treatment with metformin alone or in combination with clomiphene was not superior to clomiphene alone ${ }^{(25)}$.

Aromatase inhibitors, which block estrogen synthesis, directly affect hypothalamic-pituitaryovarian function and theoretically might increase pregnancy rates ${ }^{(5)}$. Potential advantages of aromatase inhibitors over selective estrogen-receptor modulators include a more physiologic hormonal stimulation of the endometrium, a lower multiple-pregnancy rate through single-follicle recruitment, a better side-effect profile with fewer vasomotor and mood symptoms, and more rapid clearance, thus reducing the chances of periconceptional exposure ${ }^{(5)}$.

During the past decade, letrozole (aromatase inhibitor approved by FDA for the treatment of postmenopausal women with breast cancer) has been successfully used for induction of ovulation in patients with polycystic ovary syndrome (PCOS) and for augmentation of ovulation in ovulatory women. In contrast to clomiphene citrate, letrozole is rapidly eliminated from the body and does not deplete estrogen receptors and therefore has no adverse effect on endometrium or endocervix ${ }^{(18)}$.

Several studies revealed that letrozole is superior over clomiphene citrate for superovulation in patients with PCOS ${ }^{(19)}$. Many meta-analyses of randomized controlled trials comparing aromatase inhibitors (letrozole) with clomiphene citrate for superovulation in patients with PCOS revealed that the pregnancy rate was comparable between both management options in favor of letrozole ${ }^{(20)}$.

The optimal dose and duration of letrozole administration for superovulation in patients with PCOS are still not clear.

In present study we tried to know the optimal dose and duration of the letrozole administration in patients diagnosed to have PCOS for induction of their ovulation to have pregnancy and satisfied outcome. The aim of this prospective randomized comparative study is to compare the efficacy of short and long course of letrozole therapy in induction of ovulation in women with PCOS. Results came as following:

In the present study, the mean value \pm SD for total number of follicles after stimulation was significantly greater in the long letrozole group $(6.48 \pm 0.68)$ vs. (4 \pm 0.91 ) in short letrozole group; $\mathrm{P}=0.001$ ).

These results come agree with the results of study done by Badawy et al. ${ }^{(28)}$ that was done to evaluate the outcome of long letrozole therapy for induction of ovulation in patients with clomiphene-resistant polycystic ovary syndrome (PCOS) on 218 patients with clomiphene-resistant PCOS and patients were randomly allocated to treatment with either long letrozole therapy $(\mathrm{n}=108)$ or short letrozole therapy $(n=110)$. And their results in this point were the total numbers of follicles during stimulation was significantly greater in the long letrozole group $(6.7+/$ 0.3 vs. $3.9+/-0.4$ ).

In another study was carried by Fouda et al..$^{(29)}$ on 136 women who responded poorly to GnRH agonist long protocol in their first IVF cycle and were randomized into two equal groups using computer generated list and were treated in the second IVF cycle by either extended letrozole regimen $(5 \mathrm{mg}$ /day during the first 5 days of cycle and $2.5 \mathrm{mg}$ /day during the subsequent 3 days) combined with HPuFSH-GnRHant protocol or short letrozole regimen $(2.5 \mathrm{mg} /$ day from cycle day 3-7) combined with HPuFSH-GnRHant protocol. The study was done to compare the efficacy and cost-effectiveness of extended high dose letrozole regimen/HPuFSH-gonadotropin releasing hormone antagonist (GnRHant) protocol with short low dose letrozole regimen/HPuFSH-GnRHant protocol in poor responders undergoing IVF-ET. The study showed that there were no significant differences between both groups with regard to number of oocytes retrieved in extended letrozole group and in short letrozole group $(5.39 \pm 2.08$ vs. $5.20 \pm 1.88$, respectively).

In another study was done by Ramezanzadeh $\boldsymbol{e t}$ $a{ }^{(30)}$ to compare the effects of either a 5 or $7.5 \mathrm{mg}$ daily dose of Letrozole in PCOS women undergoing ovulation induction. Sixty-seven PCOS patients with infertility were randomly divided into two groups and treated with either $5 \mathrm{mg} / \mathrm{day}$ (30 patients, group 1) or $7.5 \mathrm{mg} /$ day (37 patients, group 2) Letrozole for 5 days starting from day 3 of the menstrual cycle. The result was There no significant difference in the number of intermediate $(0.83 \pm 0.75$ vs $0.62 \pm 0.76)$ and mature follicles $(1.13 \pm 1.11$ vs $1.22 \pm 1.03)$ on days $12-14$ between group 1 and 2 , respectively.

In the present study, the mean of biggest follicles size $(\mathrm{mm})$ was greater $(19.095 \pm 2.26)$ in the long letrozole group when compared to short letrozole group $(18.83 \pm 2.12)$, without statistical differences $(\mathrm{P}=0.712)$.

In the present study, the number of patients with follicles measuring $\geq 18 \mathrm{~mm}$ and between $14-17 \mathrm{~mm}$ was greater in the long letrozole group $(\mathrm{P}=0.774)$. These results came in comparable with the results of Badawy et al. ${ }^{(28)}$.

In the present study, the mean of endometrial thickness at the time of HCG administration \pm SD in group I was $8.2 \pm 1.56 \mathrm{~mm}$ versus $8.933 \pm 1.64$ among group II. There was no significant difference in the endometrial thickness at the time of HCG administration between the two groups $(\mathrm{P}=0.081)$. That came agree with Badawy et $\boldsymbol{a l} .{ }^{(28)}$ and Ramezanzadeh et al. ${ }^{(30)}$. 
In the present study, percentage of ovulation occurred after treatment among group I group II (long letrozole group) was greater than Group I (short letrozole group) (63.3\% vs $56.7 \%$, respectively). This came agree with Badawy $\boldsymbol{e t} \boldsymbol{a l} .{ }^{(28)}$ (The number of ovulating patients was greater in the long letrozole group $(65.7 \%$ vs. $61.8 \%)$, but without statistical differences). This came in contrast with Ramezanzadeh et al. ${ }^{(30)}$ (Ovulation occurred in 90 and $89.2 \%$ of patients in group 1 and 2 ).

The present study showed that pregnancy occurred in 4 out of 30 patients in the short letrozole group $(13.3 \%)$ and in 6 out of 30 patients (20\%) in the long letrozole group. One twin pregnancy occurred in the long letrozole group (16.67\% of pregnant cases). Comparison between the 2 groups according to post treatment pregnancies was in favor of long group and $\mathrm{P}$-value was $>0.05$. These results came in comparable with Badawy et al. ${ }^{(28)}$ as their study showed that pregnancy occurred in 28 of 225 cycles in the short group (12.4\%) and 38 of 219 cycles $(17.4 \%)$ in the long letrozole group, and the difference was statistically significant. In contrast to these result, Fouda et al. ${ }^{\left({ }^{(2)}\right)}$ showed that there were no significant differences between both groups with regard to clinical pregnancy rate ( $22.06 \%$ vs. $16.18 \%$, respectively) and in disagree also with Ramezanzadeh $\boldsymbol{e t} \boldsymbol{a l .} .^{(30)}$ who showed that the pregnancy rate was $25.8 \%$ in group 1 and $21.2 \%$ in group 2 without significant difference.

Depending on results of the present study, we conclude that the long letrozole therapy ( $5 \mathrm{mg}$ for 10 days) can produce more and bigger mature follicles and better endometrial thickness and subsequently more pregnancies than the short letrozole therapy (5 days) and so, the long letrozole therapy (5 $\mathrm{mg}$ for 10 days) should take the superiority of ovulation induction in PCOS patients. This conclusion came agree with what Badawy et $\boldsymbol{a l} .{ }^{(28)}$ estimated that the long letrozole protocol (10 days) can produce more mature follicles and subsequently more pregnancies than the short letrozole therapy (5 days). This conclusion also came in comparable with Fouda et al. ${ }^{(29)}$ who decided (extended letrozole regimen/HPuFSH-GnRHant protocol was more costeffective than short letrozole regimen/HPuFSHGnRHant protocol in poor responders undergoing IVF-ET).

In contrast to our results concluded that there is difference in results between different doses of letrozole in induction of PCOS patients, Ramezanzadeh $\boldsymbol{e t} \boldsymbol{a l} .{ }^{(30)}$ estimated there is no any advantage to the use of $7.5 \mathrm{mg} /$ day over $5 \mathrm{mg} /$ day dose of Letrozole as the first line treatment for induction of ovulation in women with PCOS.
The long letrozole therapy ( $5 \mathrm{mg}$ for 10 days) can produce more and bigger mature follicles and better endometrial thickness and subsequently more pregnancies than the short letrozole therapy (5 days).

\section{REFERENCES}

1. Bozdag G (2016): The prevalence and phenotypic features of polycystic ovary syndrome: a systematic review and meta-analysis. Hum Reprod., 31(12): 28412855.

2. March W (2010): The prevalence of polycystic ovary syndrome in a community sample assessed undercontrasting diagnostic criteria. Human Reproduction, 25(2): 544-51.

3. Tsilchorozidou T, Overton C, Conway GS (2004): The pathophysiology of polycystic ovary syndrome. Clin Endocrinol., 60(1):1-17.

4. Eisenhardt S, Schwarzmann N, Henschel V (2006): Early effects of metformin in women with polycystic ovarian syndrome: A prospective randomized, double blind, placebo-controlled trial. J Clin Endocrinol Metab., 91: 946-952.

5. Casper RF and Mitwally MF (2006): Aromatase Inhibitors for Ovulation Induction. J Clin Endocrinol Metab., 91: 760-771.

6. Meinhardt U, Mullis PE (2002): The aromatase cytochrome P-450 and its clinical impact. Horm Res., 57(5-6):145-52.

7. Jie Cui, Yong Shen, and Rena Li (2013): Estrogen synthesis and signaling pathways during ageing: from periphery to brain, Trends Mol Med., 19(3): 197-209.

8. William $R$, John B Angela $M$ et al. (2008): Aromatase Inhibitors: Are There Differences Between Steroidal and Nonsteroidal Aromatase Inhibitors and Do They Matter? theoncologist.alphamedpress.org/content/13/8/829.full

9. Brodie A and Njar V (1996): Aromatase Inhibitor and breast cancer. Semin Oncol., 23: 10-20.

10. Okman K, Kucuk M, Altaner S (2003): Comparison of the effects of letrozole and clomiphene citrate on ovarian follicles, endometrium and hormone levels in the rat. Fertil Steril., 80: 1330-1332.

11. Mitwally $F$ and Casper $R$ (2001): Use of an aromatase inhibitor for induction of ovulation in patients with an inadequate response to clomiphene citrate. Fertil Steril., 75:135-139.

12. Lidor A, Goldenberg $M$, Cohen $S$ et al. (2000): Management of women with polycystic ovary syndrome who experienced premature luteinization during clomiphene citrate treatment. Fertil Steril., 74: 749-774.

13. Mitwally M, Biljan M, Casper R (2005): Pregnancy outcome after the use an aromatase inhibitor for ovarian stimulation. Am J Obstet and Gynec., 192(2): 381-386.

14. Al-Omari W, Al Hadithi N, Izat B, et al. (2001): The effect of an aromatase inhibitor on ovulation induction and endometrial receptivity in clomiphene resistant women with polycystic ovary syndrome. Mid East Fertil Soc J., 6: S2-5.

15. Marciniak A, Lejman-Larysz K, NawrockaRutkowska (2018): Polycystic ovary syndrome - 
current state of knowledge. Pol Merkur Lekarski, 44:296-301.

16. Tanbo T, Mellembakken J, Bjercke $\mathrm{S}$ (2018): Ovulation induction in polycystic ovary syndrome. Acta Obstet Gynecol Scand., 97:1162-7.

17. Kamboj MK, Bonny AE (2017): Polycystic ovary syndrome in adolescence: diagnostic and therapeutic strategies. Transl Pediatr., 6:248-55.

18. Teede H, Deeks A, Moran L (2010): Polycystic ovary syndrome: a complex condition with psychological, reproductive and metabolic manifestations that impacts on health across the lifespan. BMC Med., 8:41.

19. Cipkala-Gaffin J, Talbott EO, Song MK (2012): Associations between psychologic symptoms and life satisfaction in women with polycystic ovary syndrome. J Womens Health (Larchmt), 21:179-87.

20. Cooney LG, Dokras A (2017): Depression and anxiety in polycystic ovary syndrome: etiology and treatment. Curr Psychiatry Rep., 19:83.

21. Zhou J, Yang L, Yu J (2017): Efficacy of acupuncture on menstrual frequency in women with polycystic ovary syndrome: Protocol for a randomized, controlled trial. Randomized controlled trial. Medicine (Baltimore), 96:e8828.

22. Jirege PR, Patill RS (2010): Comparison of endocrine and ultrasound profiles during ovulation induction with clomiphene citrate and letrozole in ovulatory volunteer women. Fertil Steril., 93:174-83.

23. Fisher SA, Reid RL, Van Vugt DA et al. (2002): A Randomized double-blind comparison of the effects of clomiphene citrate and the aromatase inhibitor letrozole on ovulatory function in normal women. Fertil Steril., $78: 280-5$.

24. Al-Fozan H, Al-Khadouri M, Tan SL et al. (2004): A randomized trial of letrozole versus clomiphene citrate in women undergoing superovulation. Fertil Steril., $82: 1561-3$.

25. Legro RS, Barnhart HX, Schlaff WD (2007): Clomiphene, metformin, or both for infertility in the polycystic ovary syndrome. N Engl J Med., 356:551566.

26. Kamphuis EI, Bhattacharya S, van der Veen $\mathrm{F}$ et al. (2014): Are we overusing IVF? BMJ., 348:g252.

27. Thessaloniki ESHRE/ASRM-Sponsored PCOS Consensus Workshop Group (2008): Consensus on infertility treatment related to polycystic ovary syndrome. Fertil Steril., 89:505-522.

28. Badawy A, Mosbah A, Tharwat A et al. (2009): Extended letrozole therapy for ovulation induction in clomiphene-resistant women with polycystic ovary syndrome: a novel protocol., 92(1):236-9.

29. Fouda UM, Sayed AM (2011): Extended high dose letrozole regimen versus short low dose letrozole regimen as an adjuvant to gonadotropin releasing hormone antagonist protocol in poor responders undergoing IVF-ET. https://www.ncbi.nlm.nih.gov/pubmed/21714697

30. Ramezanzadeh $F$, Nasiri R, Sarafraz Yazdi M et al. (2011): A randomized trial of ovulation induction with two different doses of Letrozole in women with PCOS., 284:1029-1034. 